$$
\operatorname{Cosf}-930676--26
$$

\title{
Dynamical Behavior of Octahedrite from the Henbury Meteorite ${ }^{\star}$
}

\author{
Michael D. Furnish ${ }^{1}$, George T. Gray $1 I^{2}$ and John L. Remo ${ }^{3}$ \\ ${ }^{1}$ Experimental Impact Physics Dept. 1433, Sandia National Laboratories, Albuquerque NM 87185 \\ ${ }^{2}$ MST-5, G730, Los Alamos National Laboratory, Los Alamos NM 87545 \\ ${ }^{3}$ Quantametrics, Inc., Brackenwood Path, Head of the Harbor, St. James, NY 11780
}

A suite of dynamic property measurements and characterization studies on an iron-nickel single crystal from the Henbury octahedrite containing Widmanstätten intergrowths of kamacite and taenite (initial density 7.810) has been performed. These measurements include six impact tests (wave profile compression/release) over the stress range $2-20 \mathrm{GPa}$, metallography, quasi-static and Hopkinson bar mechanical testing, and ultrasonic mapping and sound velocity measurements. A cryogenic impact test was included to evaluate effects of a brittle/ductile transition which has been reported at $200 \mathrm{~K}$. Temperature sensitivity of the dynamic behavior was measured at high and low strain rates. The impact test results show loading strength (HEL), Hugoniot and $\alpha \rightarrow \varepsilon$ transition signatures to be similar to those for Armco iron, and do not show evidence for a ductile-brittle transition at these extremely high strain rates. Metallographic analyses, quasi-static and Hopkinson bar testing suggest that the material is in a work-hardened state and that kamacite properties dominate the bulk octahedrite properties.

\section{INTRODUCTION}

The dynamic response of materials representative of meteors, asteroids and comets is of interest for a variety of problems, most notably, those concerned with the origin of asteroids, with the deflection of large meteors or asteroids on Earthintercepting paths, or with the modeling of terrestrial or extraterrestrial impact events.

Samples of the Henbury octahedrite were selected for testing as representative of the large class of iron-nickel meteorites. This central Australian fall, dated about 3,000 BC[1], has a composition roughly $7.5 \mathrm{wt} \% \mathrm{Ni}, 0.4 \mathrm{wt} \% \mathrm{Co}$ and $94 \% \mathrm{Fe}$ (with traces of $\mathrm{P}, \mathrm{C}, \mathrm{S}, \mathrm{Cr}, \mathrm{Cu}, \mathrm{Ge}, \mathrm{Ir}, \mathrm{Ga}$ and $\mathrm{Zn}$.)

The microstructure of the Henbury consists of large lamellar kamacite, (bcc-phase; nickel-poor) and mixed regions of taenite and plessite (fccphases; nickel-rich) as shown in Figure 1. Numerous deformation twins, labeled " $\mathrm{A}$ " in Figure 1, are seen within the kamacite lamellae. This microstructure is consistent with that previously documented as typical in octahedrite meteorites, such as the Henbury $[1,2]$. Previous studies have shown the

\footnotetext{
*Sponsored by the U.S. Department of Energy and conducted under the auspices of the U. S. Department of Energy under Contract DE-AC04-76DP00789.
}

Henbury to consist of $\sim 70-80$ vol.\% kamacite and 20-30\% taenite and plessite[1], with minor schreibersite $\left((\mathrm{Fe}, \mathrm{Ni})_{3} \mathrm{P}\right)$ precipitates and occasional troilite nodules.

\section{IMPACT EXPERIMENTS}

\section{Method and Matrix}

A suite of six impact tests was designed to allow the observation of strength effects, the Hugoniot, the $\alpha \rightarrow \varepsilon$ transition (in the bcc kamacite com-

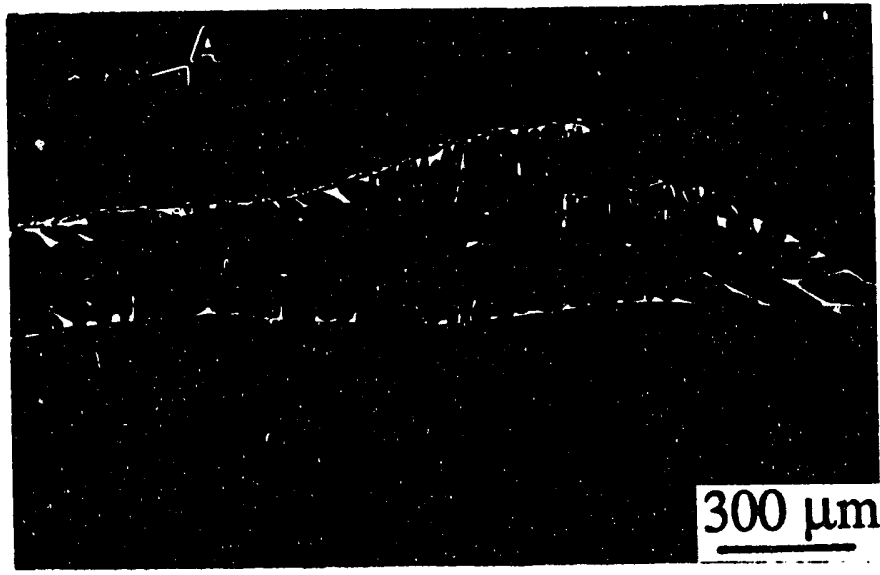

Figure 1. Optical metallography of the Henbury showing deformation twins (labeled " $\mathrm{A}$ ") in the

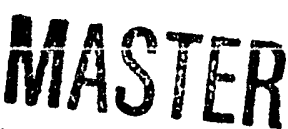
kamacite.

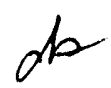




\section{DISCLAIMER}

This report was prepared as an account of work sponsored by an agency of the United States Government. Neither the United States Government nor any agency thereof, nor any of their empicyees, makes any warranty, express or implied, or assumes any legal liability or responsibility for the accuracy, completeness, or usefulness of any information, apparatus, product, or process disclosed, or represents that its use would not infringe privately owned rights. Reference herein to any specific commercial product, process, or service by trade name, trademark, manufacturer, or otherwise does not necessarily constitute or imply its endorsement, recommendation, or favoring by the United States Government or any agency thereof. The views and opinions of authors expressed herein do not necessarily state or reflect those of the United States Government or any agency thereof. 
ponent), release properties and whether important effects of a brittle/ductile transition which has been reported at $200 \mathrm{~K}$ are present. The configurations used are shown schematically in Fig. 2, with important dimensions given in Table 1.

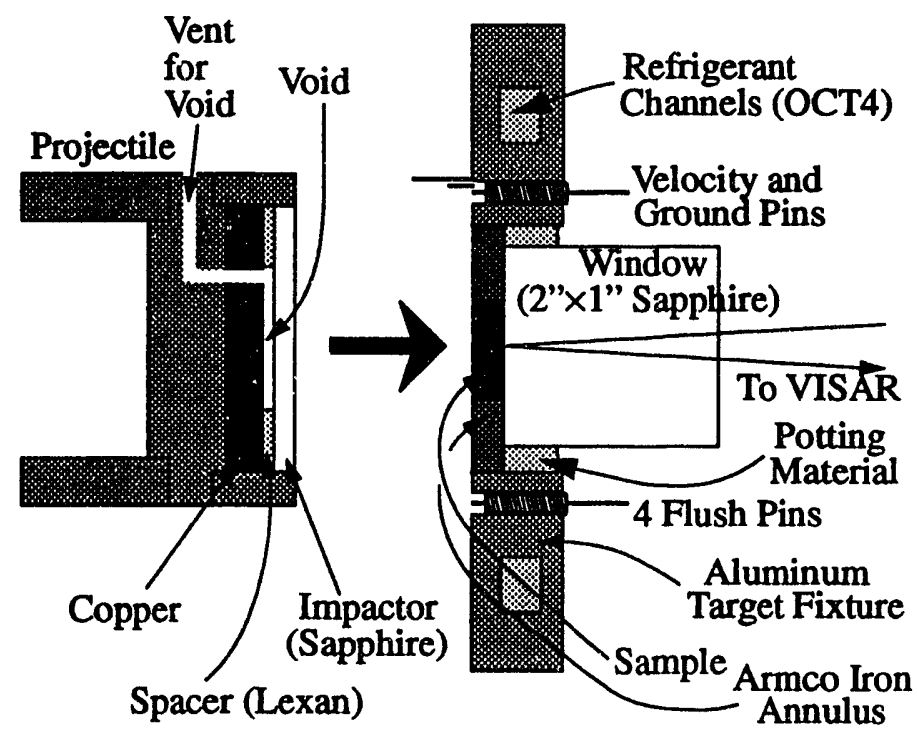

Typical Setup (OCT 1, 2, 4)

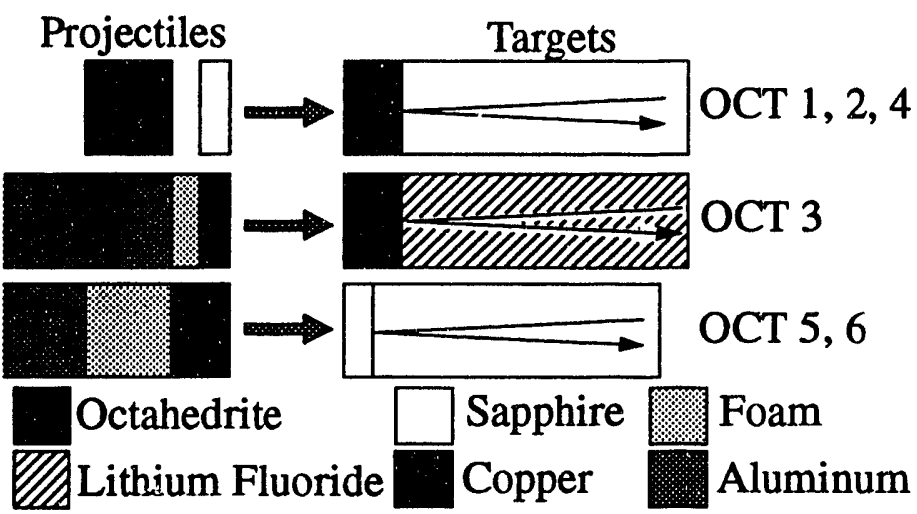

Sandwich Configurations Used

Figure 2. Impact Configurations Used

\section{Results}

The three lower-velocity transmitted waveform tests gave the waveforms shown in Figure 3 (timed according to ultrasonic sound velocity measurements of samples).

The highest-velocity transmitted waveform is shown in Fig. 4 (note that this experiment utilized a $\mathrm{LiF}$ window). Of particular interest are the elastic precursors (amplitude $0.9 \mathrm{GPa}$ ) and the waveform morphology. The waveforms do not suggest an increased brittle component in the $163 \mathrm{~K}$ test (OCT

\begin{tabular}{|l|l|l|l|l|}
\hline Test $\rightarrow$ & OCT1 & OCT2 & OCT4 & OCT3 \\
\hline \multicolumn{5}{|c|}{ Projectile (thicknesses in mm) } \\
\hline Cu backer & 3.199 & 3.205 & 3.189 & $12.649(\mathrm{Al})$ \\
\hline Space & 0.095 & 0.254 & 0.301 & $4.973(\mathrm{Foam})$ \\
\hline Sapphire & 3.193 & 3.193 & 3.189 & $1.647(\mathrm{Cu})$ \\
\hline \multicolumn{5}{|c|}{ Target (thicknesses in mm) } \\
\hline Sample & 4.999 & 5.006 & 4.996 & 4.999 \\
\hline Window & 25.40 & 25.40 & 25.40 & $25.29(\mathrm{LiF})$ \\
\hline \multicolumn{5}{|c|}{ Shot parameters $(\mathrm{m} / \mathrm{sec})$} \\
\hline Impact Vel. & 107 & 312 & 311 & 993 \\
\hline VPF & 40.334 & 40.608 & 40.608 & 55.995 \\
\hline \hline Test $\rightarrow$ & OCT5 & OCT6 \\
\hline \multicolumn{5}{|c|}{ Projectile (thicknesses in mm) } \\
\hline Al Noseplate & 3.199 & 3.205 \\
\hline 20\# Foam & 0.095 & 0.254 \\
\hline Sample & 3.193 & 3.193 \\
\hline \multicolumn{5}{|c|}{ Target (thicknesses in mm) } \\
\hline Sapphire Buffer & 4.999 & -5.006 \\
\hline Sapphire Window & 25.40 & 25.40 \\
\hline \multicolumn{5}{|c|}{ Shot parameters (m/sec) } \\
\hline Impact Vel. & 107 & 312 \\
\hline VPF & 40.334 & 40.608 \\
\hline
\end{tabular}

Table 1. Parameters for Impact Tests

4) over the corresponding $300 \mathrm{~K}$ test (OCT2).

Two reverse-ballistic (sample in projectile) experiments w/ere conducted to provide a check on Hugoniot measurements as well as further information on release paths.

Hugoniot results are summarized in Table 3 for this material. In all cases, the starting density is

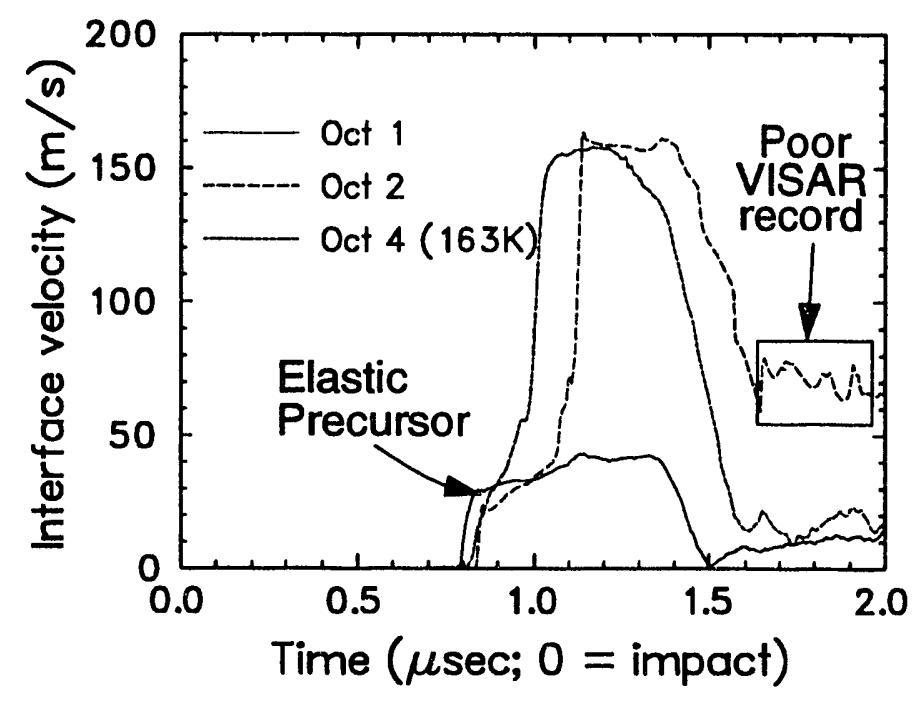

Figure 3. Forward-Ballistic Waveform (Sapphire window experiments) 

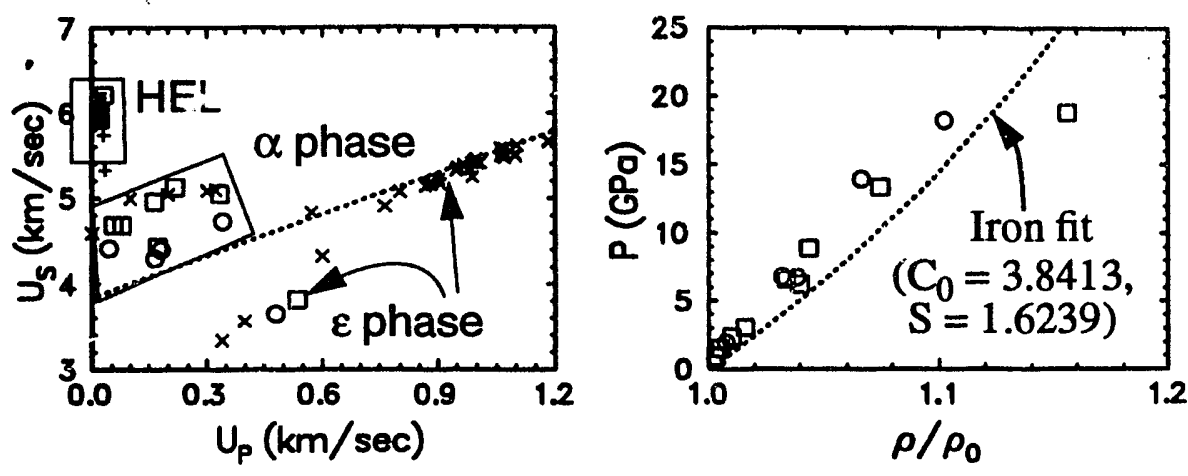

Figure 5. Hugoniot of Henbury Octahedrite. Iron Hugoniot for comparison. Lagrangian analysis of Hugoniot state in OCT 3 is questionable because of large sample-window impedance mismatch.

$\square \bigcirc$ Present Data (Impedance match,
Lagrange analysis, resp.)
$+\times$ Armio and other Iron $(\bar{\rho}=7.85)$

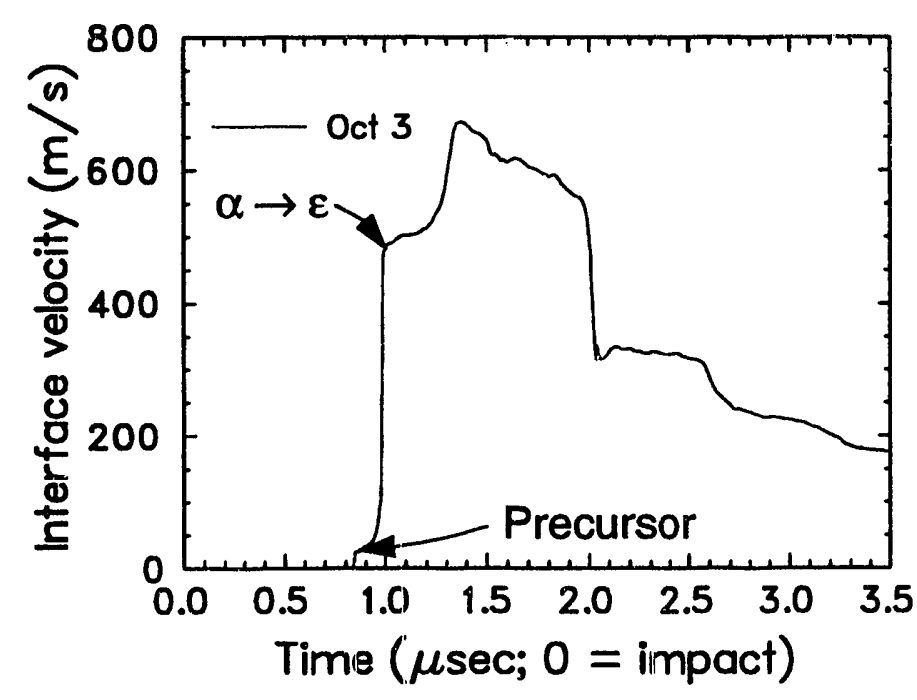

Figure 4. Forward-Ballistic Waveform (Lithium fluoride window experiment)

\begin{tabular}{|c|c|c|c|c|}
\hline $\begin{array}{c}\text { Test } \\
\#\end{array}$ & $\begin{array}{c}\text { Particle } \\
\text { Vel. km/s }\end{array}$ & $\begin{array}{l}\text { Stress } \\
\text { GPa }\end{array}$ & $\begin{array}{l}\text { Density } \\
\mathrm{gm} / \mathrm{cm}^{3}\end{array}$ & $\begin{array}{c}\text { Shock } \\
\text { Vel. km/s }\end{array}$ \\
\hline OCT1 & 0.055 & 2.37 & 7.90 & 4.69 \\
\hline OCT2 & 0.174 & 6.24 & 8.13 & 4.44 \\
\hline OCT3 & 0.537 & 18.80 & 9.04 & 3.82 \\
\hline OCT4 & 0.166 & 6.57 & 8.09 & 4.97 \\
\hline OCT5 & 0.078 & 3.05 & 7.95 & 4.69 \\
\hline OCT6 & 0.218 & 8.85 & 8.17 & 5.13 \\
\hline \multicolumn{5}{|c|}{$\alpha \rightarrow \varepsilon$ state } \\
\hline OCT3 & 0.335 & 13.34 & 8.41 & 5.05 \\
\hline \multicolumn{5}{|c|}{ Elastic precursor states } \\
\hline OCT1 & 0.031 & 1.51 & 7.862 & 6.21 \\
\hline OCT2 & 0.020 & 0.93 & 7.849 & 5.92 \\
\hline OCT3 & 0.019 & 0.90 & 7.848 & 5.96 \\
\hline OCT4 & 0.020 & 0.93 & 7.849 & 6.01 \\
\hline
\end{tabular}

Table 2. Hugoniot states for Henbury octahedrite. taken as $7.82 \mathrm{gm} / \mathrm{cm}^{3}$. For the reverse-ballistic tests (OCT 5 and 6), a precursor of amplitude $0.9 \mathrm{GPa}$ and wavespeed $6 \mathrm{~km} / \mathrm{sec}$ was assumed.

These Hugoniots are plotted against Armco iron data in Figure 5. Lagrangian analysis results and standard $\mathrm{P} / \mathrm{U}_{\mathrm{P}}$ impedance match results are included; only the latter are tabulated in Table 2.

Wavecode modeling of the two reverse-ballistic waveforms (Fig. 6), assuming a strength of 0.51 GPa and no phase transitions, produces good agreement with the observed veiocity history. Agreement could be further improved by assuming a more dispersive lower release in OCT 6.

\section{OTHER CHARACTERIZATIONS}

The true stress-true strain response of the Henbury was measured at both quasi-static strain rates $\left(\sim 10^{-3} \mathrm{~s}^{-1}\right)$ and using a split-Hopkinson pressure bar $\left(3000 \mathrm{~s}^{-1}\right)$ at 77 and $298 \mathrm{~K}$. The yield strength and work-hardening behavior of the Henbury meteorite are seen to depend on the strain rate and temperature of loading (Figure 7).

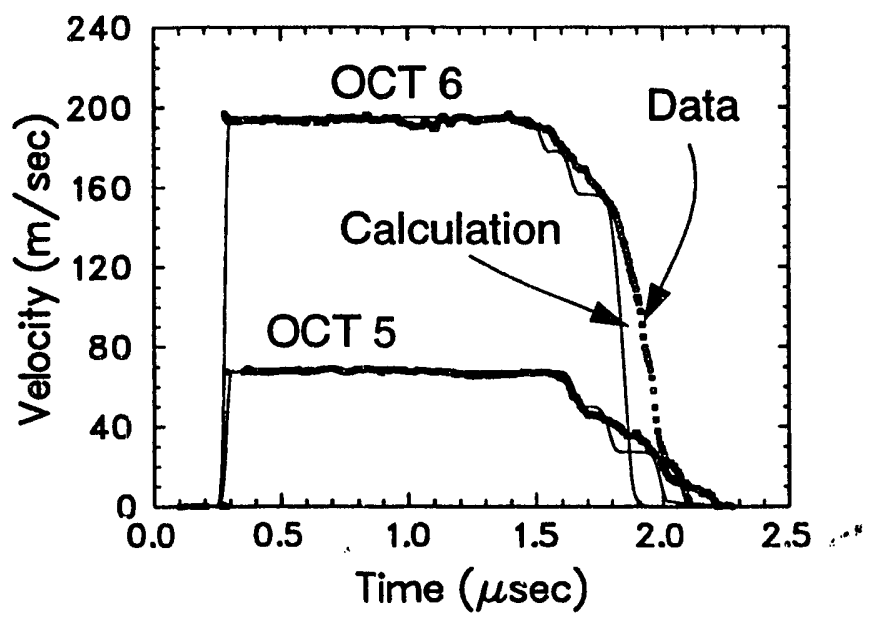

Figure 6. Reverse-ballistic waveforms with corresponding Mie-Grüneisen modeling 


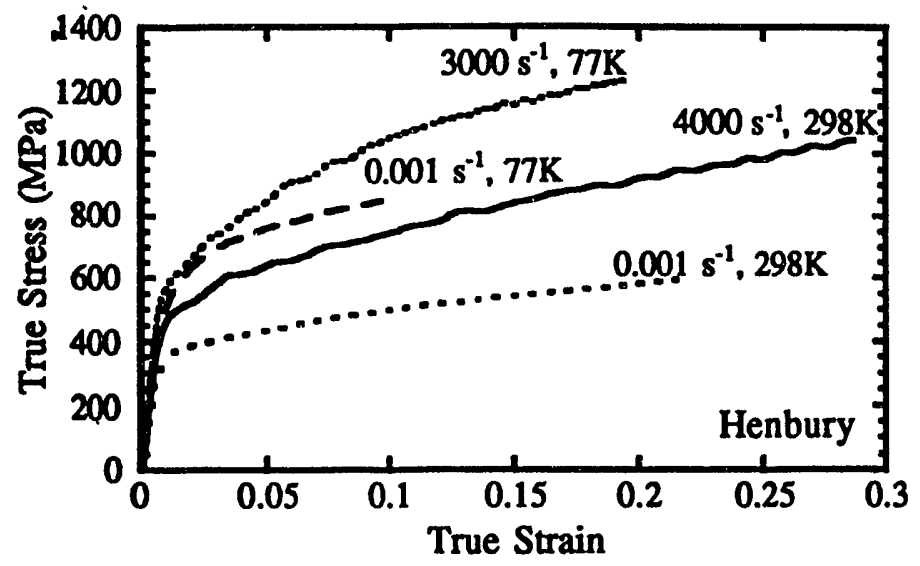

Figure 7. Stress-strain response of Henbury as a function of temperature and strain rate.

Ultrasonic studies were also conducted with the samples prepared for impact testing. A course $(2-8 \mathrm{~mm})$ banded, granular structure is apparent in mappings of the longitudinal velocity and attenuation, with longitudinal velocity variations ranging up to $7 \%$ across the samples. Transducer shear velocity measurements made with the particle motion polarized along the bands gave sound velocities averaging 0.85 of the velocities measured for the perpendicular particle velocity motion. Transducer measurements of the longitudinal velocity were also made; these were increased by $15 \mathrm{~m} / \mathrm{sec}$ to give the HEL velocities of Table 2 .

\section{DISCUSSION}

Compared to its constituents the $\sim 300 \mathrm{MPa}$ yield strength at $0.001 \mathrm{~s}^{-1}$ and $298 \mathrm{~K}$ suggests that the Henbury is in a work-hardened state. A rule-ofmixtures approximation to stress-strain data for pure $\mathrm{Ni}$ and $\mathrm{Fe}$ shows that $\sim 15 \%$ true strain must be present in the meteorite to have a $300 \mathrm{MPa}$ yield. This hardening is clearly related to the deformation twins and dislocation substructure in both phases. Definitive determination of the exact origin of this substructure however, including the twins, is difficult. While both earth cratering impact and very old events associated with parent break-up can both cause significant shock pulses in meteorites, previous studies suggest it is primarily preatmospheric [3]. Cosmic collisions remote in time and space are thought to generate the majority of the substructures and hardening seen in most meteor- ites[3].

In addition, the yield strength of the Henbury is seen to increase from nominally $300 \mathrm{MPa}$ to $\sim 425$ MPa with increasing strain rate at $298 \mathrm{~K}$ or increase to $\sim 550 \mathrm{MPa}$ during low or high-rate testing at $77 \mathrm{~K}$. Increasing strain rate or decreasing temperature result in an increased level of work-hardening consistent with the suppression of dynamic recovery processes. The rate and temperature sensitivity of the yield stress is consistent with: a) the bulk mechanical response of the Henbury being controlled by the primary constituent, the bcc kamacite, and b) the work-hardened state of the Henbury overall leading to an increased rate and temperature sensitivity compared to annealed metals.

The strengths derived from the impact wave profiles $\left(Y=\sigma_{\mathrm{HEL}} \cdot(1-2 v) /(1-v) ; n \equiv\right.$ Poisson's ratio) of $450 \mathrm{MPa}$ are consistent with the Hopkinson bar measurements, as well as with Armco iron data[4].

The $\alpha$ to $\varepsilon$ transition was observed in the only impact test above $13 \mathrm{GPa}$. Its level $(13.34 \mathrm{GPa})$ is similar to that reported for Armco iron (13 GPa [4]), with a slight elevation possibly due to nickel content. The density increase observed here $(7 \%)$ is similar to that for Armco iron. There is, however, a puzzling post-Hugoniot decay in this waveform which may represent kinetics of the $\alpha \rightarrow \varepsilon$ transition or micromechanical relaxation.

Finally, we do not find evidence in the wave profiles for the brittle - ductile transition inferred at $\sim 200 \mathrm{~K}[2]$. This is not surprising considering that the present studies probed the high rate constitutive response of the Henbury rather than fracture processes. Fracture events depend critically on yield/ failure surface interactions which can be stress state dependent and were not considered.

\section{REFERENCES}

[1] V.F. Buchwald, in Handbook of Iron Meteorites, U. of California Press, Berkeley (1975) vol. 2, pp. 642, 643.

[2] J.L. Remo and A.A. Johnson, J. Geophysical Res., 80, pp. 3744-3748 (1975).

[3] V.F. Buchwald, in Handbook of Iron Meteorites, U. of Calif. Press, Berkeley (1975) vol. 1, pp. 90.

4] L. M. Barker and R. E. Hollenbach, J. Appl. Phys., 45, 4872-4887, 1974. 

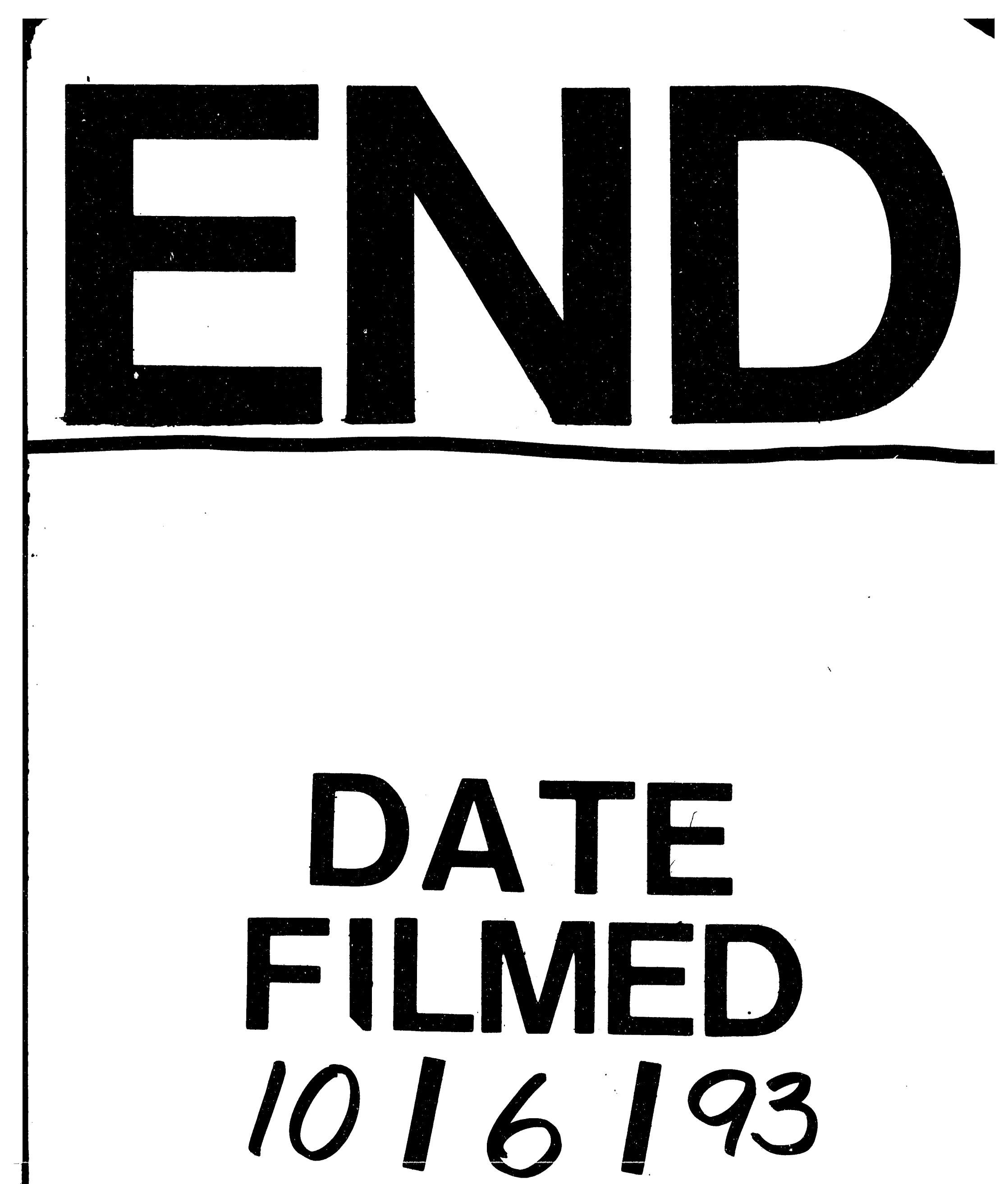


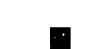

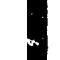 \\ A

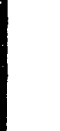

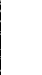 \\ . \\ . \\ .

